\title{
Prevalence of group B streptococcus colonization in pregnant women in Jiangsu, East China
}

\author{
Yanmei Ge ${ }^{1 \dagger}$, Fei Pan ${ }^{2 \dagger}$, Rui Bai ${ }^{1}$, Yuan Mao ${ }^{2}$, Wenli $\mathrm{Ji}^{1}$, Fenfang Wang ${ }^{2}$ and Huacheng Tong ${ }^{1 *}$ (D)
}

\begin{abstract}
Background: Group B streptococcus (GBS) is the leading cause of early-onset neonatal sepsis. However, GBS was infrequently reported in the developing world in contrast to western countries. This study assessed the prevalence of GBS colonization among pregnant women in Jiangsu, East China, and revealed the difference of GBS infection between culture and PCR.

Methods: A total of 16,184 pregnant women at 34 to 37 weeks' gestation aged 16-47 years were recruited from Nanjing Kingmed Center for Clinical Laboratory. Nine thousand twenty-two pregnant women received GBS screening by PCR detection only. Seven thousand one hundred sixty-two pregnant women received GBS screening by bacterial culture and GBS-positive samples were tested for antibiotic resistance.

Results: The overall GBS positive rate was $8.7 \%$ by PCR and $3.5 \%$ by culture. Colonization rate was highest in the "25-29 years" age group. The 249 GBS-positive samples which detected by culture were all sensitive to penicillin. The prevalence of resistance to erythromycin, clindamycin, and levofloxacin was 77.5, 68.3, and 52.2\%, respectively.

Conclusions: This study revealed the data on the prevalence of GBS colonization in pregnant women at 34 to 37 weeks' gestation in Jiangsu, East China. It compared the difference of the sensitivity to detect GBS between PCR and culture. PCR was expected to become a quick method in pregnancy women conventional detection of GBS infection.
\end{abstract}

Keywords: Group B streptococcus, Prevalence, Colonization, Antibiotic resistance

\section{Background}

Group B streptococcus (GBS) is the main pathogen of perinatal infection. It is not only the leading cause of early-onset neonatal sepsis and meningitis (first 28 days of life), but also has been associated with preterm labor, premature rupture of membranes, chorioamnionitis, and puerperal and fetal infections in many countries [1-3]. Screening of pregnant women for GBS colonization during the third trimester, coupled with targeted

\footnotetext{
* Correspondence: gym8902@163.com

†Yanmei Ge and Fei Pan contributed equally to this work.

${ }^{1}$ Nanjing Tongren Hospital, School of Medicine, Southeast University, Nanjing 211102, China

Full list of author information is available at the end of the article
}

intrapartum antibiotic prophylaxis (IAP) of colonized women during labor, has reduced the incidence of invasive GBS disease in western countries [4]. GBS detection and identification has become more commonplace, due to the availability of polymerase chain reaction (PCR) technology [5]. However, the traditional method of culture of GBS is still the gold standard.

Penicillin and clindamycin are the first line of antibiotic recommendations in most countries. Penicillin, ampicillin, and cefepime are the main drugs of choice to treat GBS infection in China. Vancomycin, macrolides (such as erythromycin, azithromycin, and clarithromycin), and lincosamides (clindamycin) may be used as the

(c) The Author(s). 2021 Open Access This article is licensed under a Creative Commons Attribution 4.0 International License, which permits use, sharing, adaptation, distribution and reproduction in any medium or format, as long as you give appropriate credit to the original author(s) and the source, provide a link to the Creative Commons licence, and indicate if changes were made. The images or other third party material in this article are included in the article's Creative Commons licence, unless indicated otherwise in a credit line to the material. If material is not included in the article's Creative Commons licence and your intended use is not permitted by statutory regulation or exceeds the permitted use, you will need to obtain permission directly from the copyright holder. To view a copy of this licence, visit http://creativecommons.org/licenses/by/4.0/ The Creative Commons Public Domain Dedication waiver (http://creativecommons.org/publicdomain/zero/1.0/) applies to the data made available in this article, unless otherwise stated in a credit line to the data. 
alternative drugs for patients allergic to penicillin or cephalosporins [6-9].

In this study, we investigated the GBS colonization rate in pregnant women in Jiangsu, China. At the same time, we compared the difference in the detection rate of GBS between the two methods of culture and PCR and described the sensitivity of GBS to different antibiotics.

\section{Methods}

\section{Study population}

Our study is retrospective study. Between June of 2017 and June of 2019, pregnant women at 34 to 37 weeks' gestation who resided in Jiangsu Province and received GBS screening at Nanjing Kingmed Center for Clinical Laboratory were studied. The pregnant women had not received antibiotic treatment for at least 2 weeks before recruitment into the study [10]. We performed an analysis of 16,184 women aged 16-47 years, including 9022 pregnant women who received GBS screening by PCR and 7162 by culture. GBS-positive samples were tested for antibiotic resistance by automatic microbial identification and drug sensitivity analysis system.

\section{Specimen collection}

A set of vagino-rectal swab samples consisting of two swabs were taken. The specific operation steps were carried out according to the method recommended by the 2002 CDC. The accurately labeled swabs were placed in a cooler box containing ice packs, and transported to the laboratory at Nanjing Kingmed Center within 2-4h of collection. Specimens were collected by an obstetrician and taken as part as standard care, for 2 years from 16,184 pregnant women.

\section{PCR assays}

GBS DNA was detected using the Group B Streptococcus (GBS) nucleic acid detection kit (BioChain (Beijing) Science \& Technology. Inc.). Firstly, each vaginal or rectal swab specimen was combined with $1 \mathrm{ml}$ of normal saline $(0.9 \% \mathrm{NaCl}) .500 \mu \mathrm{l}$ of the vaginal specimen was mixed with $500 \mu \mathrm{l}$ of rectal swab specimen. DNA was extracted from the mixed liquid following the manufacturer's instructions, then $100 \mathrm{ng}(5 \mu \mathrm{l})$ GBS DNA was used as a template and added into $35 \mu$ reaction mixture. Primer and probe referred to the previous study [11]. The conditions for the PCR were as follows: $50^{\circ} \mathrm{C}$ for $2 \mathrm{~min}$, initial denaturation $95^{\circ} \mathrm{C}$ for $5 \mathrm{~min}, 45$ cycles of PCR at $95^{\circ} \mathrm{C}$ for $15 \mathrm{~s}$ and $60^{\circ} \mathrm{C}$ for $35 \mathrm{~s}$. Positive reactions were defined as a cycle threshold $(\mathrm{CT})<38$. Negative control reactions (no DNA template) were included with every run. PCR was done on an ABI PCR system 7500 version 2.3 for the amplification.

\section{Microbiology (culture)}

Cotton swab samples (a set of vagino-rectal swab samples) from pregnant mothers were inoculated into Todd-Hewitt culture broth, subcultured on Columbia blood agar to which 5\% sheep blood has been added (Oxoid, United Kingdom), then incubated at $37^{\circ} \mathrm{C}$ in ambient air for 24-48 h. The colonies on the solid media were presumptively identified as Group B Streptococcus if they forming light red to dark red colonies on CHROMagarStrepB.

\section{Antimicrobial susceptibility test}

GBS-positive samples were tested for antibiotic resistance by VITEK 2 Compact system (France). The disk diffusion method was used to measure resistance to penicillin, ampicillin, cefepime, cefotaxime, ergomycin, clindamycin, chloramphenicol, linezolid, vancomycin, and levofloxacin according to the Clinical and Laboratory Standards Institute (CLSI) standards [12].

\section{Statistical analysis}

Statistical analyses were performed using SPSS version 19.0 (IBM, Armonk, NY, USA). GBS positive rate was estimated by a proportion and summarized as a percentage and proportions compared using exact binomial 95\% confidence intervals $(95 \% \mathrm{CI})$. The chi-squared $\left(x^{2}\right)$ was used to compare the proportions of different age groups. A $p$-value of $<0.05$ was considered statistically significant.

\section{Results}

\section{The prevalence of GBS infection}

A total of 16,184 pregnant women were enrolled in the study. Seven hundred eighty-nine participants (8.7, 95\% CI: $8.2-9.3 \%$ ) out of 9022 women studied by PCR showed GBS colonization, while 249 (3.5, 95\% CI: 3.1$3.9 \%)$ of 7162 women investigated by the culture were colonized (Table 1). The average positive rate of GBS infection is $6.4 \%$ (95\% CI: $6.0-6.8 \%$ ).

\section{Prevalence of GBS colonization among pregnant women of different age groups}

The analysis of the prevalence of positive GBS results was presented by different age groups ( $\leq 24$ years, $25-29$ years, $30-34$ years, $35-39$ years, and $\geq 40$ years). There were both no obvious difference among different age groups by PCR $(P=0.161)$ and by culture $(P=0.28)$.

Table 1 The prevalence of GBS infection in all the specimens

\begin{tabular}{llll}
\hline Participants & Total & Positive & \% (95\%Cl) \\
\hline PCR & 9022 & 789 & $8.7(8.2-9.3)$ \\
Culture & 7162 & 249 & $3.5(3.1-3.9)$ \\
\hline
\end{tabular}


The highest prevalence was found in the "25-29 years" age group (9.4, 95\% CI: 8.5-10.4\%), while the lowest prevalence was found in the "younger than 24 years" age group (7.5, 95\% CI: 6.3-8.6\%) based on the PCR method. However, based on the culture method, the prevalence rates were 3.6 and $3.2 \%$, respectively. However, the group with the highest frequency was found in the "older than 40 years" age group (7.1, 95\% CI: $2.0-12.3 \%)$, based on the culture method. This group ( $\geq 40$ years) showed a smaller difference in the prevalence rates between the culture method and PCR method (1.6\%), meanwhile, this difference was greater than $4 \%$ in the other groups (Table 2).

\section{Antimicrobial susceptibility}

Antimicrobial susceptibility testing identified all samples detected by microbiology as susceptible to penicillin, linezolid, and vancomycin. The prevalence of resistance to erythromycin, clindamycin, and levofloxacin was 77.5 , 68.3 , and $52.2 \%$, respectively (Table 3 ).

\section{Discussion}

This study showed a low prevalence of GBS colonization in pregnant women in Jiangsu, East China. Colonization rate was highest among $25-29$ years old by PCR, and culture. Our study also identified higher rates by PCR than by culture. PCR may, therefore, be expected to become a quick method to detect those at risk of GBS colonization in pregnancy compared to conventional detection of GBS infection. The GBS-positive samples which detected by culture were all sensitive to penicillin.

GBS infection can be transient or persistent during pregnancy, which inevitably leads to different results of GBS in the same pregnant woman at different times of pregnancy $[1,13]$. Therefore, we should choose the same stage of pregnant women when studying the infection rate of GBS. There are regional differences in GBS colonization in pregnant women. For example, the reported prevalence of GBS for Africa is 22.4\%, Southeast Asia is $11.1 \%$ and Taiwan is $23.7 \%$ [14, 15].
Table 3 The sensitivity of GBS to different antibiotic

\begin{tabular}{lllll}
\hline Antibiotic & Total & $\mathbf{S}(\%)$ & $\mathbf{I}(\%)$ & $\mathbf{R}(\%)$ \\
\hline Penicillin & 249 & $249(100.0)$ & $0(0.0)$ & $0(0.0)$ \\
Ampicillin & 246 & $243(98.8)$ & $0(0.0)$ & $3(1.2)$ \\
Cefepime & 250 & $247(98.8)$ & $0(0.0)$ & $3(1.2)$ \\
Cefotaxime & 235 & $233(99.1)$ & $0(0.0)$ & $2(0.9)$ \\
Erythromycin & 249 & $50(20.1)$ & $6(2.4)$ & $193(77.5)$ \\
Clindamycin & 249 & $76(30.5)$ & $3(1.2)$ & $170(68.3)$ \\
Chloramphenicol & 250 & $226(90.4)$ & $7(2.8)$ & $17(6.8)$ \\
Linezolid & 249 & $249(100.0)$ & $0(0.0)$ & $0(0.0)$ \\
Vancomycin & 244 & $244(100.0)$ & $0(0.0)$ & $0(0.0)$ \\
Levofloxacin & 224 & $103(46.0)$ & $4(1.8)$ & $117(52.2)$ \\
\hline
\end{tabular}

$S$ susceptible, $I$ intermediate, $R$ resistance

Unfortunately, large-scale multicenter epidemiological studies on maternal GBS colonization in mainland China are still rare [5].

So far, there have been many regional studies on the rate of GBS colonization in China. It was reported that the prevalence of GBS for Beijing was 7.1\% and Qingdao in Shandong Province was $10.61 \%$ in Northern China [16, 17]; Shanghai was $3.7 \%$ and Nanjing was $4.16 \%$ in Eastern China [18, 19]; Chongqing was $7.05 \%$ and Chengdu in Sichuan Province was 5.02\% in Southern China $[20,21]$. The infection rates of GBS vary widely in different parts of China, and the prevalence of GBS in the northern region is significantly higher than in the eastern region. In our study, the rate of GBS colonization obtained by culture was $3.5 \%$ and that by PCR was $8.7 \%$, in Jiangsu, China. The average positive rate of GBS infection was $6.4 \%$. The rate in our study was lower than the northern region. The main reason for this difference may be related to local economic levels and environmental factors. Another important factor is the neglect of the detection method of GBS.

In our study, the rate of GBS colonization obtained by culture only $(3.5 \%)$ was much lower than the rate obtained by PCR $(8.7 \%)$ in Jiangsu, China. This is mainly

Table 2 Prevalence of GBS colonization in different age groups

\begin{tabular}{llllll}
\hline Age Groups (Years) & \multicolumn{2}{l}{ PCR } & & \multicolumn{2}{l}{ Culture } \\
\cline { 2 - 3 } \cline { 5 - 6 } & $\mathbf{n}$ (Postive/Total) & Prevalence Rate $\mathbf{( 9 5 \% ~ C l )}$ & & $\mathbf{n}$ (Postive/Total) & Prevalence Rate (95\% Cl) \\
\hline$\leq 24$ & $148 / 1982$ & $7.5(6.3-8.6)$ & $54 / 1710$ & $3.2(2.3-4.0)$ \\
$25-29$ & $377 / 3991$ & $9.4(8.5-10.4)$ & $8.6(7.4-9.8)$ & $124 / 3398$ & $3.6(3.0-4.3)$ \\
$30-34$ & $189 / 2193$ & $8.8(6.7-10.8)$ & $49 / 1527$ & $3.2(2.3-4.1)$ \\
$35-39$ & $64 / 730$ & $8.7(3.7-13.7)$ & $15 / 429$ & $3.5(1.8-5.2)$ \\
$\geq 40$ & $11 / 126$ & & $7 / 98$ & $7.1(2.0-12.3)$ \\
$P$ & 0.161 & & 0.28 & \\
\hline
\end{tabular}

Cl confidence interval

Compare the age groups with the highest and lowest prevalence rate by $P C R, P=0.011$

Compare the age groups with the highest and lowest prevalence rate by Culture, $P=0.034$ 
because PCR is a rapid method which more sensitive and specific than culture. It may be due to the presence of nonviable GBS or low bacterial load in vaginal swabs, which cannot be detected by culture, but their DNA could be present for PCR amplification [22, 23]. Some pregnant women colonized by GBS might be missed only using a culture method.

Among the different age groups, the "25-29 years" age group had the highest colonization rate and should pay more attention. It may be related to the sexually active life, history of induced abortion, and higher estrogen levels during pregnancy in these age groups. These factors can cause micro-environmental changes in the genital tract bacteria. This phenomenon will continue to focus on future research. The " $\geq 40$ years" age group showed a smaller difference in the prevalence rates between the culture method and PCR method (1.6\%), meanwhile, this difference was greater than $4 \%$ in the other groups. This may be due to the fact that this group ( $\geq 40$ years) included a fewer cases for statistical analysis. So, the results of this group ( $\geq 40$ years) were not suitable for comparative analysis.

IAP agents and dosing should be administered based on the test results of GBS among pregnant women according to the Centers for Disease Control (CDC) guidelines. Penicillin remains the agent of choice for IAP, with ampicillin as an acceptable alternative in China. Antimicrobial susceptibility testing should be ordered for antenatal GBS cultures performed on penicillinallergic women at high risk for anaphylaxis. Then, the sensitive antibiotic could be chosen according to the results of antimicrobial susceptibility testing.

Previous studies on GBS bacteremia in adults from 2002 to 2010 in the USA had shown that erythromycin and clindamycin resistance occurred in 43.6 and 39.7\% of cases, respectively [24]. And the prevalence of resistance to erythromycin and clindamycin from Taiwan for the period $2006-2008$ was 58.3 and $57.9 \%$, respectively [25]. In our study, the prevalence of resistance to erythromycin and clindamycin was 77.5 and $68.3 \%$, respectively. It was higher than the prior studies. The goal of our research is pregnant women at 34 to 37 weeks' gestation, which is a special group of people. It may be the main cause of this difference.

\section{Conclusion}

In the present study, we presented the data on the prevalence of GBS colonization in pregnant women at 34 to 37 weeks' gestation in Jiangsu, East China. At the same time, we compared the difference of GBS colonization between culture and PCR. Such data could guide interventions to control the prevalence of GBS. IAP agents and dosing should be administered according to the test results of GBS among pregnant women. As expected from the literature PCR has a higher sensitivity than culture, but does not allow assessment of antibiotic sensitivity. The very low prevalence of penicillin resistance suggests that PCR might be a very efficient screening test. Culture could be reserved to those pregnant women with allergy to penicillin.

\section{Abbreviation}

GBS: Group B Streptococcus; IAP: Intrapartum antibiotic prophylaxis; PCR: Polymerase chain reaction; $\mathrm{Cl}$ : Confidence interval

\section{Acknowledgments}

We would like to thank Nanjing Kingmed Center for Clinical Laboratory for providing the data used in this paper.

\section{Authors' contributions}

FP and YMG carried out the sample collections, laboratory detection and drafted the manuscript. YMG and HCT drafted and revised the manuscript. $\mathrm{RB}, \mathrm{YM}, \mathrm{WL}$ and FFW participated in the design of the study and the statistical analysis. All authors read and approved the final manuscript.

\section{Funding}

No funding was obtained for this study.

\section{Availability of data and materials}

The data and materials used during the study are available from the corresponding author on reasonable request.

\section{Declarations}

Ethics approval and consent to participate

This study was approved by the Ethics Committee of Nanjing Kingmed Center for.

Clinical Laboratory. The Ethics Committee of Nanjing Kingmed Center for Clinical Laboratory concluded that no informed consent was required because the data are anonymized appropriately.

\section{Consent for publication}

Not applicable.

\section{Competing interests}

The authors declare that they have no competing interests.

\section{Author details}

${ }^{1}$ Nanjing Tongren Hospital, School of Medicine, Southeast University, Nanjing 211102, China. ${ }^{2}$ Nanjing Kingmed Center for Clinical Laboratory Co., Ltd, Nanjing 210043, China.

Received: 26 March 2020 Accepted: 14 May 2021

Published online: 27 May 2021

\section{References}

1. Verani JR, McGee L, Schrag SJ, Division of Bacterial Diseases, National Center for Immunization and Respiratory Diseases, Centers for Disease Control and Prevention (CDC). Prevention of perinatal group B streptococcal disease-revised guidelines from CDC, 2010. MMWR Recomm Rep. 2010; 59(RR-10):1-36.

2. Edwards MS, Baker CJ. Streptococcus agalactiae (group B streptococcus). In: Bennett JE, Dolin R, Blaser MJ, editors. Mandell, Douglas, and Bennett's principles and practice of infectious diseases. 8th ed. Philadelphia: Elsevier/ Saunders; 2015: 2340-2348.

3. Cunningham FG, Leveno KJ, Bloom SL, Spong CY, Dashe JS, Hoffman BL, et al., editors. Williams obstetrics. 24nd ed. New York: McGraw-Hill Education/Medical; 2014:1249-51.

4. Schrag SJ, Schuchat A. Easing the burden: characterizing the disease burden of neonatal group B streptococcal disease to motivate prevention. Clin Infect Dis. 2004;38(9):1209-11. https://doi.org/10.1086/382889.

5. Huang J, Lin X-Z, Zhu Y, Chen C. Epidemiology of group B streptococcal infection in pregnant women and diseased infants in mainland China. Pediatr Neonatol. 2019. https://doi.org/10.1016/j.pedneo.2019.07.001. 
6. de Azavedo JC, McGavin M, Duncan C, Low DE, Mcgeep A. Prevalence and mechanisms of macrolide resistance in invasive and noninvasive group B Streptococcus isolates from Ontario, Canada. Antimicrob Agents Chemother. 2001:45(12):3504-8. https://doi.org/10.1128/AAC.45.12.3504-3508.2001.

7. von Both U, Buerckstuemmer A, Fluegge K, Berner R. Heterogeneity of genotype-phenotype correlation among macrolide-resistant Streptococcus agalactiae isolates. Antimicrob Agents Chemother. 2005;49(7):3080-2. https://doi.org/10.1128/AAC.49.7.3080-3082.2005.

8. Chohan L, Hollier LM, Bishop K, Kilpatrick CC. Patterns of antibiotic resistance among group B Streptococcus isolates: 2001-2004. Infect Dis Obstet Gynecol. 2006;2006:57492.

9. Heelan JS, Hasenbein ME, McAdam AJ. Resistance of group B Streptococcus to selected antibiotics, including erythromycin and clindamycin. J Clin Microbiol. 2004;42(3):1263-4. https://doi.org/10.1128/JCM.42.3.1263-1264.2004.

10. Chukwu MO, Mavenyengwa RT, Monyama CM, Bolukaoto JY, Lebelo SL, Maloba MRB, et al. Antigenic distribution of Streptococcus agalactiae isolates from pregnant women at Garankuwa hospital - South Africa. GERMS. 2015; 5(4):125-33. https://doi.org/10.11599/germs.2015.1080.

11. Breeding KM, Ragipani $B$, Lee KD, et al. Real-time PCR-based serotyping of Streptococcus agalactiae. Sci Rep. 2016;6(1):38523. https://doi.org/10.1038/ srep38523.

12. CLSI. Performance standards for antimicrobial susceptibility tests; approved standard, 12th ed. M100-S20-U. Wayne, Pennsylvania, USA: Clinical and Laboratory Standards Institute; 2010.

13. Di RG, Melin P, Berardi A, Blennow M, Carbonellestrany X, Donzelli GP, et al. Intrapartum GBS screening and antibiotic prophylaxis: a European consensus conference. J Matern Fetal Med. 2014;28:766-82.

14. Kwatra G, Cunnington MC, Merrall E, Adrian PV, Ip M, Klugman KP, et al. Prevalence of maternal colonisation with group B streptococcus: a systematic review and meta-analysis. Lancet Infect Dis. 2016;16(9):1076-84. https://doi.org/10.1016/S1473-3099(16)30055-X.

15. Hsu JF, Chen CL, Lee CC, Lien R, Chu SM, Fu RH, et al. Characterization of group B Streptococcus colonization in full-term and lete-preterm neonates in Taiwan. Pediatr Neonatol. 2018;51875-9572(18):30059-7.

16. Lu B, Li D, Cui Y, Sui W, Huang L, Lu X. Epidemiology of group B streptococcus isolated from pregnant women in Beijing, China. Clin Microbiol Infect. 2014:20:370-3.

17. Wang $X$. The relation between maternal colonization of group $B$ streptococcus in late pregnancy and the pregnancy outcome. J Baotou Med Coll. 2015;31:34-5.

18. Chen HH, Fan JX, Lu TY, Xu TY. Effect of group B streptococcus infection on pregnant women and their infants. Shanghai Med J. 2009;32:128-30.

19. Ji XQ, Lu GS, Hu P, Cheng J, Liu Y, Lin Y. Colonization of group B Streptococcus in late pregnancy by fluorescence quantitation PCR in Nanjing area. Lab Med. 2014;29:628-30.

20. He JW, Zhang Y, Chen M, Yuan Y, Fan C, Li QQ, et al. Effect of group B streptococcus infection on pregnant women of different reproductive ages in Chongqing. Int J Lab Med. 2016:37:2784-6.

21. Jidi AY, Ma J, Tong W, Xiao XL. Risk factors for group B streptococcus colonization among pregnant women and effectiveness of intrapartum antibiotic prophylaxis on maternal and newborn outcomes. J Clin Med Pract. 2017:21:194-6.

22. Atkins KL, Atkinson RM, Shanks A, Parvinn CA, Dunne WM, Gross G. Evaluation of polymerase chain reaction for group $B$ streptococcus detection using an improved culture method. Obstetr Gynecol. 2006;108(3, Part 1):488-91.

23. Ostroff RM, Steaffens JW. Effect of specimen storage, antibiotics, and feminine hygiene products on the detection of group B Streptococcus by culture and the STREP B OIA test. Diagn Microbiol Infect Dis. 1995;22(3):2539. https://doi.org/10.1016/0732-8893(95)00046-D.

24. Kaseman JA, Myers NM, Miracle JE, Myers JP. Group B streptococcal bacteremia in adults in the 21st century: review of 132 episodes over a 10year period in a large community teaching hospital. Infect Dis Clin Pract. 2013;21 (2):105-10. https://doi.org/10.1097//PC.0b013e318279ee4f.

25. Wang YH, Su LH, Hou JN, Yang TH, Lin TY, Chu C, et al. Group B. streptococcal disease in nonpregnant patients: emergence of highly resistant strains of serotype lb in Taiwan in 2006 to 2008. J Clin Microbiol. 2010;48(7):2571-4. https://doi.org/10.1128/JCM.00810-10.

\section{Publisher's Note}

Springer Nature remains neutral with regard to jurisdictional claims in published maps and institutional affiliations.

\section{Ready to submit your research? Choose BMC and benefit from:}

- fast, convenient online submission

- thorough peer review by experienced researchers in your field

- rapid publication on acceptance

- support for research data, including large and complex data types

- gold Open Access which fosters wider collaboration and increased citations

- maximum visibility for your research: over $100 \mathrm{M}$ website views per year

At BMC, research is always in progress.

Learn more biomedcentral.com/submissions 